\title{
Investigating interfaces: an experimental approach to focus in Sicilian Italian
}

Raffaella Folli ${ }^{1}$ and Elinor Payne ${ }^{2}$

${ }^{1}$ School of Communication, University of Ulster, UK

${ }^{2}$ Department of Phonetics and Linguistics, University College London, UK

https://doi.org/10.36505/ExLing-2006/01/0027/000027

\begin{abstract}
This paper describes an investigation of the syntax-prosody interface in the expression of focus in Sicilian Italian. It finds evidence of a generalised reversal of the articulation of information structure, with new information often preceding old, and of intonational differentiation between focus types.
\end{abstract}

\section{Introduction}

A pressing question in current linguistic theory is how different components of language interact. Our investigation considers the prosody and syntax interaction in the expression of focus. A major challenge for interface studies is reconciling differences in methodology and theoretical approach inherent in each discipline. This is particularly true for an investigation of focus, a phenomenon particularly difficult to elicit under experimental controls.

Our study examines focus in two varieties of Sicilian Italian. This variety is of particular interest because, although the 'default' word order (i.e. for 'broad focus') is VO, as in other varieties of Italian, a very frequent OV order is attested with the expression of New Information Focus (see Poletto and Benincà, 2002 and Cruschina, 2006). This again contrasts with Italian where the typical partition of a sentence sees the old information preceding the new information (see example 1), while the preverbal position is typically available only for Contrastive Focus (see example 2):

(1) A. Cosa mangia Gianni?

'What does John eat?'

B. Gianni mangia una mela

'John eats an apple'

(2) A Gianni mangia una pera?

John eats a pear?

No, una mela mangia

No, an apple he eats

It has been argued that in Sicilian Italian a preverbal position can be targeted not only by contrastively focused material, but also by new information focus.

ExLing 2006: Proceedings of 1st Tutorial and Research Workshop on Experimental Linguistics, 28-30 August 2006, Athens, Greece 
For example, Cruschina (2004: 33) reports that in the dialect of Mussomeli (in the province of Caltanisetta) the following order is attested:
A. Chi successi?
What happened?
B Ruppi a seggia (Broad Focus)
He broke the chair
What did Salvo break?
B. A seggia ruppi (New Information Focus)
The chair he broke
C. A SEGGIA ruppi (Contrastive Focus)
THE CHAIR he broke

(4) A. Chi ruppi Salvo?

(4) shows that the preverbal position can be occupied both by the constituent carrying new information and contrastive focus, giving rise to an OV order in (4)B which is unattested in Standard Italian. Cruschina claims that, though these two types of focus are semantically distinct, in Sicilian they are indistinguishable syntactically. He claims, from impressionistic analysis, that the two are, nevertheless, prosodically distinct (i.e. they have a different intonational contour) and argues that this distinction at the prosodic level confirms the existence of two distinct syntactic positions.

We conducted a detailed instrumental analysis of these two types of focus to investigate whether such a prosodic difference actually exists and gain insight into whether or not they can be conflated into a unified syntactic position (Frascarelli, 2000). Our investigation also extended to other kinds of syntactic environment, varying verb type (transitives, unaccusatives, unergatives) to test for sensitivities at the interface to the different relationship between phrase constituents.

\section{Experiment \\ Material}

The material consisted of sentences constructed to provide data that conformed both to syntactic/semantic requirements and phonetic/phonological conditions (e.g. all segments voiced, to allow tracing of pitch contour).

\section{Procedure}

\section{Subjects}

The 12 subjects were all students at Catania University ${ }^{1}$, from Catanese families, and familiar with dialect. Subjects were chosen on the basis of their 
performance in an initial test, conducted to ascertain how naturally they produced OV order in the relevant context.

\section{Elicitation technique}

Subjects were presented with a series of questions, and asked to construct answers using words printed on small cards which were placed in front of them, in random order. For example, for the question 'cosa fa Anna?', subjects saw the cards 'MANGIARE' (eat) + 'ANNA' + 'MELA' (apple).

To elicit the most natural responses possible, one experimenter (from Catania) was dedicated to asking the questions. This was to avoid any interference that hearing non-Sicilian accents could import, and to focus her attention on building a rapport with the subject. Another experimenter manipulated the priming cards, and another controlled the recording.

\section{Results}

Preliminary results from an analysis using PRAAT reveal intonation differences between new information and contrastive focus, for focus on subject, verb or object. Figure 1 shows this difference for focus on unergative verbs.
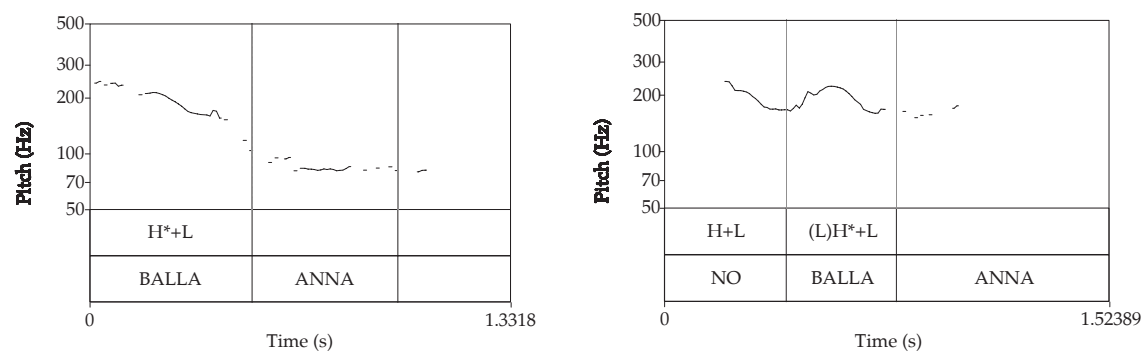

Figure 1. Pitch contours of new information focus on balla (left) and contrastive focus (right) on balla

New Information Focus on balla ('dances') attracts a FALL $\left(\mathrm{H}^{*+} \mathrm{L}\right)$, aligned with the beginning of the stressed syllable. When focus is contrastive, the $\mathrm{H}^{*}$ is aligned later in the stressed syllable, indicating the same underlying phonological sequence $\left(\mathrm{H}^{*}+\mathrm{L}\right)$, but different phonetic alignment. Some evidence indicates also a preceding $\mathrm{L}$, which would be interpretable either as a pragmatically specific Phrase Accent $\left(\mathrm{L} \mathrm{H}^{*}+\mathrm{L}\right)$, or part of what is actually a tritonal, RISE-FALL Nuclear Pitch Accent $\left(\mathrm{L}+\mathrm{H}^{*}+\mathrm{L}\right)$.

For subjects, New Information Focus appears to have the same basic pitch accent $\left(\mathrm{H}^{*}+\mathrm{L}\right)$ as Broad Focus. The difference is that in the latter, this is a pre-nuclear pitch accent, and the nucleus falls at the end of the phrase (e.g. $\left(\mathrm{H}^{*+\mathrm{L}}\right)$ Anna ha il $\left(\mathrm{H}^{*}+\mathrm{L}\right)$ libro), while in the former the pitch accent on Anna is nuclear and everything else that follows is de-accented (e.g. 
$\left(\mathrm{H}^{*}+\mathrm{L}\right) A N N A$ ha il libro. $)$. As with verbs, contrastive focus on subjects attracts what is either a RISE-FALL $\left(\mathrm{L}+\mathrm{H}^{*+} \mathrm{L}\right)$, or an $\mathrm{L}$ Phrase Accent $\left(\mathrm{L} \mathrm{H}^{*+\mathrm{L}}\right)$.

\section{Preliminary conclusions}

The evidence points to a reversal in the articulation of information structure in this variety when compared with Standard Italian: often in Catanese Italian new information precedes old information. This appears to be true not just for object-initial sentences, but also when other constituent types are fronted (e.g. subjects or verbs).

From an initial analysis, it would appear that the two types of focus, new information and contrastive, are indeed distinguishable prosodically at the production level, though this distinction remains to be confirmed perceptually. It is also remains to be shown whether this distinction lies within the Nuclear Pitch Accent itself, or is expressed through a form of Phrase Accent associated with contrast. It is noted that some form of pragmatic markedness is associated with the left peripheral new information focus, whereby this order is often employed to reconfirm or strongly emphasise a piece of new information. This opens the question, which we are currently investigating, as to whether these two types of focus target two distinct syntactic positions in the left peripheral $\mathrm{C}$ field, or whether the prosodic difference is the only cue to interpretation. In other words, could this be an example of a trading relation between intonation and syntax?

\section{Notes}

${ }^{1}$ Recordings were also made in Palermo, where it proved far more difficult to elicit $\mathrm{OV}$ order, and these data will serve principally as a benchmark for the intonation analysis. The confounding factor was most likely sociolinguistic, with perceived greater aspirations among subjects to standardise their speech.

\section{Acknowledgements}

This research was funded by a British Academy Small Research Grant. We would also like to thank Sebastiano Grasso and Maria Catena Costa from Catania University and Mari D'Agostino from Palermo University for their kind assistance with recordings.

\section{References}

Cruschina, S. (forthcoming), Informational focus in Sicilian. To appear in $\mathrm{M}$. Frascarelli (ed.), Phases of Interpretation. Berlin, Mouton.

Frascarelli, M. 2000. The Syntax-Phonology Interface in Focus and Topic Constructions in Italian. Kluwer Academic Publishers.

Poletto, C. and Benincà, P. 2002. Topic, Focus and V2: defining the CP sublayers, in L. Rizzi (ed.) (2004) The structure of IP and CP. Vol. 2, OUP. 